University of Wollongong

Research Online

Faculty of Engineering and Information

Faculty of Engineering and Information

Sciences - Papers: Part A

Sciences

$1-1-2016$

\title{
Analytical solution for interaction forces in beams strengthened with near- surface mounted round bars
}

Shi Shun Zhang

University of Wollongong, shishun@uow.edu.au

Tao Yu

University of Wollongong, taoy@uow.edu.au

Follow this and additional works at: https://ro.uow.edu.au/eispapers

Part of the Engineering Commons, and the Science and Technology Studies Commons

Research Online is the open access institutional repository for the University of Wollongong. For further information contact the UOW Library: research-pubs@uow.edu.au 


\title{
Analytical solution for interaction forces in beams strengthened with near- surface mounted round bars
}

\author{
Abstract \\ The use of near-surface mounted (NSM) FRP composites for strengthening RC beams in flexure has \\ become increasingly popular in the last decade. Compared to the externally bonded (EB) FRP \\ strengthening method, the bond between FRP and concrete is much stronger when the NSM FRP \\ strengthening method is used. However, debonding is still a likely failure mode in RC members \\ strengthened with NSM FRP bars. The debonding in an NSM FRP-strengthened beam may initiate from \\ either of the two ends of an NSM bar (i.e. end debonding) in the form of interfacial debonding or concrete \\ cover separation, both of which are closely related to the existence of large localized interaction forces \\ between the NSM bar and concrete near the bar ends in such beams. This paper presents an analytical \\ solution for the interaction forces in RC beams strengthened with NSM FRP round bars, which are one of \\ the most popular types of FRP bars used for NSM strengthening. The key elements of the proposed \\ analytical solution are two interfacial stiffness parameters (i.e. tangential interfacial stiffness and normal \\ interfacial stiffness). The validity of the proposed analytical solution is also verified using a sophisticated \\ 3D FE model of a RC beam strengthened with a NSM round bar.

\section{Disciplines} \\ Engineering | Science and Technology Studies

\section{Publication Details} \\ Zhang, S. S. \& Yu, T. (2016). Analytical solution for interaction forces in beams strengthened with near- \\ surface mounted round bars. Construction and Building Materials, 106 189-197.
}




\title{
Analytical Solution for Interaction Forces in Beams Strengthened
}

\author{
with Near-Surface Mounted Round Bars
}

\author{
S.S. Zhang* and T. Yu \\ School of Civil, Mining and Environmental Engineering, University of Wollongong, \\ Northfields Avenue, Wollongong, NSW 2522, Australia \\ (*Corresponding author: shishun@uow.edu.au)
}

Abstract: The use of near-surface mounted (NSM) FRP composites for strengthening RC beams in flexure has become increasingly popular in the last decade. Compared to the externally bonded (EB) FRP strengthening method, the bond between FRP and concrete is much stronger when the NSM FRP strengthening method is used. However, debonding is still a likely failure mode in RC members strengthened with NSM FRP bars. The debonding in an NSM FRP-strengthened beam may initiate from either of the two ends of an NSM bar (i.e. end debonding) in the form of interfacial debonding or concrete cover separation, both of which are closely related to the existence of large localized interaction forces between the NSM bar and concrete near the bar ends in such beams. This paper presents an analytical solution for the interaction forces in RC beams strengthened with NSM FRP round bars, which are one of the most popular types of FRP bars used for NSM strengthening. The key elements of the proposed analytical solution are two interfacial stiffness parameters (i.e. tangential interfacial stiffness and normal interfacial stiffness). The validity of the proposed analytical solution is also verified using a sophisticated 3D FE model of a RC beam strengthened with a NSM round bar.

Keywords: Near-surface mounted (NSM), round bars, interaction forces, analytical modeling, finite element analysis 
28 In the past two decades, fibre-reinforced polymer (FRP) composites have become increasingly popular for flexural strengthening of reinforced concrete (RC) beams [e.g. 1-4. The most common way of FRP strengthening of RC beams in flexure is to externally bond (EB) FRP onto the soffit of a beam. This method has been extensively studied, and guidelines have been established for design use. More recently, the near-surface mounted (NSM) FRP strengthening technique has attracted significant attention worldwide as one of the promising new techniques for structural strengthening and as an effective alternative to the externally bonded FRP technique [e.g. 1, 5]. The NSM FRP technique involves cutting grooves in the concrete cover, filling the grooves with adhesive, and embedding FRP bars into the grooves [1]. FRP bars of various cross-sectional shapes may be used in the NSM strengthening, among which round and rectangular bars have been most commonly used. A typical schematic of NSM FRP for flexural strengthening of RC beams is shown in Fig. 1. Compared to the EB FRP method, the NSM FRP method has a number of advantages including better protection of the FRP reinforcement and a much stronger bond between FRP and concrete [6]. However, the improved bond effectiveness does not preclude the possibility of debonding failure of NSM FRP bars, and indeed debonding is still a likely failure mode in RC members strengthened with NSM FRP bars [e.g. 3]. The debonding in an NSM FRP-strengthened beam may initiate from a major intermediate crack (i.e. IC debonding), or from either of the two ends of an NSM bar (i.e. end debonding). For the latter case which is more often observed, 47 the failure may be in the form of interfacial debonding which occurs near the 48 adhesive-to-concrete interface, or in the form of concrete separation where the NSM CFRP 49 bars and the concrete cover are torn off along the level of the steel tension reinforcement (as shown in Fig. 2). Both plate end cover separation and interfacial debonding are closely related to the existence of large localized interaction forces between the NSM bar and 
concrete near the ends of the bar in such strengthened RC beams [7].

53

54 For RC beams strengthened in flexure with EB FRP/steel plates (referred to as "plated RC beams” for brevity), a large number of closed-form analytical solutions have been developed for the interfacial shear and normal stresses. These include analytical solutions based on the direct deformation compatibility consideration [e.g. 8-16], solutions based on a staged analysis approach [e.g. 17-20] and solutions based on the complementary energy approach [e.g. 21-23]. Among these analytical solutions, Smith and Teng's solution [10] appears to be one of the most cited solution because of its accuracy and relatively simple form. This solution by Smith and Teng [10] has been used by many researchers as a standard reference solution to verify results from their own solutions, and has also been extended to consider additional issues such as thermal loading [e.g. 11], the shear deformation effect [e.g. 12-15] and beam curvature [18]. Recently, Zhang and Teng [7] proposed a closed-form solution for the interfacial interaction forces in RC beams strengthened with NSM rectangular FRP bars based on Smith and Teng's solution [10]. Zhang and Teng's solution [7] includes the establishment of approximate equations for the interfacial stiffness parameters, and has been demonstrated by a 3D linear elastic finite element (FE) model.

69

This paper aims to develop closed-form analytical solutions for the interaction forces in RC beams strengthened with NSM round FRP bars. The present study generally follows the approach taken by Zhang and Teng [7] for NSM rectangular bars, with the establishment of interfacial stiffness parameters being a key issue. 
Smith and Teng [10] developed analytical solutions for interfacial stresses in FRP/steel plated RC beams, which is essentially a plain stress problem with the width of the adhesive layer being equal to that of the FRP/steel plate and the thickness of the adhesive layer being a constant. Smith and Teng [10] assumed the interfacial stresses to be constant across the width and thickness of the adhesive layer, and obtained closed-form solutions for both interfacial shear stresses and interfacial normal stresses based on deformation compatibility.

83

Different from plated RC beams, the adhesive layer is not a plane layer in an RC beam strengthened with an NSM FRP bar. Such an NSM FRP-strengthened beam is therefore a truly 3-D problem. In order to derive a closed-form solution for such beams by extending Smith and Teng's solution [10], Zhang and Teng [7] proposed to simplify this problem into a plane stress problem (Fig. 3). To do this, Zhang and Teng [7] introduced a pair of interfacial interaction forces per unit length of the NSM bar-to-concrete interface (i.e. $F_{t}$ and $F_{n}$, see Fig. 3). Here, $F_{t}$ and $F_{n}$ are the interaction forces in the tangential direction and the normal (vertical) direction respectively; subscripts $t$ and $n$ denote the tangential and the normal directions respectively. Correspondingly, Zhang and Teng [7] also introduced two interfacial stiffness parameters, namely, the tangential interfacial stiffness $k_{t}$ and the normal

94 interfacial stiffness $k_{n}$ (Fig. 3b), which are defined to be the interfacial interaction forces between the NSM bar and concrete per unit length corresponding to a unit relative 96 displacement between the NSM bar and concrete in the designated direction (see Fig. 4). In 97 order to obtain $k_{t}$ and $k_{n}$, the following procedure was adopted by Zhang and Teng [7]: (1) 98 obtaining the stress distribution within the adhesive layer using finite element (FE) analysis; 99 and (2) calculating $k_{t}$ and $k_{n}$ by integrating stresses along the mid-thickness path of the 100 adhesive layer, based on results from the FE analysis. With the interfacial stiffnesses $k_{t}$ and 
$k_{n}$ obtained above for NSM bar-to-concrete interface, Smith and Teng's solution [10] can be

102 extended for NSM FRP-strengthened concrete beams.

103

104 Zhang and Teng's approach [7] was shown to perform well for beams strengthened with rectangular NSM FRP bars. However, when a round bar is used for NSM strengthening, the thickness of adhesive layer is typically non-uniform over the perimeter of the bar (Fig. 1). It

107 is thus inconvenient to use the mid-thickness path of adhesive layer for integration of stresses 108 as did by Zhang and Teng [7] to obtain the interfacial stiffness. Therefore, instead of 109 integrating stresses, the interfacial stiffness parameters were obtained directly based on their 110 definitions (see above) in the present study, making use of FE models. According to the

111 definitions of interfacial stiffness parameters, the interaction force between the NSM bar and

112 concrete per unit length needs to be found out for a unit relative displacement between the

113 two in the designated direction. Therefore, the FE models consisted of an NSM round bar, the 114 surrounding adhesive layer and the groove surface which was set to be a fixed boundary of 115 the adhesive layer. With such FE models, the interfacial stiffness was just equal to the total 116 reaction force of the boundary (i.e. the groove surface) when a unit displacement (i.e. $1 \mathrm{~mm}$ ) 117 was applied to the NSM bar in the designated direction. Details of the FE models are further 118 discussed later.

In summary, the analysis approach adopted in the present study differs from Zhang and

121 Teng's approach[7] in the way used to obtain the interfacial stiffness parameters. Once the 122 two interfacial stiffness parameters were obtained, the analytical solutions original developed 123 by Smith and Teng [10] and adjusted by Zhang and Teng [7] for rectangular NSM FRP 124 bar-strengthened beams can be directly applied here. In the following sections, Zhang and 125 Teng's version [7] of the governing equations and solutions is first presented, followed by 
determination of the two interfacial stiffness parameters particularly for round NSM FRP bars. The analytical solution with the newly proposed interfacial stiffness parameters are then verified by a sophisticated 3D FE model of RC beam strengthened with an NSM round bar.

\section{DIFEERENBTIAL GOVERNING EQUATIONS AND SOLUTIONS}

131 By incorporating the interaction forces and interfacial stiffness parameters defined above into the governing equations presented by Smith and Teng [10] for plated beams, the following governing equations were obtained by Zhang and Teng [7] for RC beams strengthened with

NSM bars subjected to a uniformly distributed load (UDL) q:

$$
\begin{aligned}
& \frac{d^{2} F_{t}(x)}{d x^{2}}-k_{t}\left(\frac{d_{o}^{2}}{E_{b} I_{b}+E_{f} I_{f}}+\frac{1}{E_{b} A_{b}}+\frac{1}{E_{f} A_{f}}\right) F_{t}(x) \\
& \quad-k_{t}\left(\frac{d_{o}}{E_{b} I_{b}+E_{f} I_{f}}\right) V_{T}(x)=0 \\
& \frac{d^{4} F_{n}(x)}{d x^{4}}+k_{n}\left(\frac{1}{E_{b} I_{b}}+\frac{1}{E_{f} I_{f}}\right) F_{n}(x)+k_{n}\left(\frac{y_{b}}{E_{b} I_{b}}-\frac{y_{f}}{E_{f} I_{f}}\right) \frac{d F_{t}(x)}{d x} \\
& +k_{n} \frac{1}{E_{b} I_{b}} q=0
\end{aligned}
$$

137 where $x$ is the distance from the NSM bar end in the longitudinal direction; $E_{f}, A_{f}$ and $I_{f}$ are the elastic modulus, cross-sectional area and second moment of area of the NSM FRP reinforcement respectively; $E_{b}, A_{b}$ and $I_{b}$ are the elastic modulus, cross-sectional area and second moment of area of the original beam respectively; $E_{a}, G_{a}$, and $t_{a}$ are the elastic modulus, shear modulus and thickness of the adhesive layer respectively; $d_{o}$ is the distance between the centroids of the original beam and the NSM bar; $y_{b}$ and $y_{f}$ are the

143 eccentricities of the tangential interaction forces to the centroid of the beam and that of the 144 NSM bar respectively; and $V_{T}$ is the shear force in the beam. 
146

147

148

149

150

151

152

153

154

155

156

157

158

159 where $M_{T}(0)=\frac{q a}{2}(L-a)$ and $V_{T}(0)=q\left(\frac{L}{2}-a\right)$ are the total bending moment and the total shear

160 force in the strengthened beam at $x=0$ (i.e. at the NSM bar end) respectively, $L$ and $a$

161 are the span of the beam and the distance from the bar end to the nearest support respectively. 
163 It is evident that all the parameters in Eqs. 3 to 13 are directly related to either the material

164 properties of FRP/concrete or the geometric properties and can thus be easily determined,

165 except for (1) the two interfacial stiffness parameters, and (2) the eccentricities of tangential

166 interaction forces which are not explicitly available due to the irregular shape of the adhesive

167 layer. The determination of these parameters is detailed in the following section.

168

169 INTERFACIAL STIFFNESS PARAMETERS

170 General Consideration

171 As discussed earlier, FE models were developed to obtain the two interfacial stiffness

172 parameters. Each FE model consisted of a round NSM bar centrically placed in a square

173 groove, which is the most commonly adopted configuration in the existing studies [1]. In

174 these FE models, the materials (i.e. FRP and adhesive) are assumed to be linear-elastic as

175 Smith and Teng's solution [10] was developed for elastic materials. The NSM bar was treated

176 as a rigid body as the deformation in this system is mainly within the adhesive layer which is

177 much softer. In the present study, the unit of force is Newton $(\mathrm{N})$ and the unit of length is

178 millimeter (mm) unless otherwise specified.

179

\section{Tangential Interfacial Stiffness}

FE model

183 Fig. 4b shows a schematic of the FE models used to obtain the tangential interfacial stiffness.

184 To achieve a state of pure shear, the adhesive layer is restrained against displacements in the

185 two transverse detections (i.e. only displacements in the longitudinal direction are allowed). 
186 To save the computation time, the length of the models was set to be $0.1 \mathrm{~mm}$ instead of the

187

188

189

190

191

192

193

194

195

196

197

198

199

200

201

202

203

204 unit length of $1 \mathrm{~mm}$; the reaction force obtained from these FE models was then multiplied by 10 to obtain the reaction force corresponding to a unit length. As the adhesive layer was under pure shear, such treatment does not affect the accuracy of the results.

Fig. 5 shows the mesh of a typical FE model (i.e. specimen T-D6-W9). Both the adhesive layer and the FRP bar were modelled using 8-node solid elements with a full Gauss integration. The mesh was obtained using the "structured mesh technique" provided by ABAQUS [24]. The size of element was constant in the longitudinal direction, but varied slightly over the cross-sectional planes due to the irregularity of the adhesive layer, especially for the regions close to the intersections between the diagonals of the groove and the circumference of the bar (i.e. the regions surrounded by the dotted circles in Fig. 5).

A mesh convergence study was conducted to decide on the suitable meshes for the FE models used in the present study. The resulting mesh from the convergence study had an element size of $0.05 \mathrm{~mm}$ in the longitudinal direction, and had an approximate global mesh size [24] of 0.1 $\mathrm{mm}$ in the cross-sectional planes. The approximate global mesh size here provides a rough global control of the mesh; the actual element size is dependent on the geometry of the object to be meshed and is close to the approximate global mesh size. The actual element size in the cross-sectional planes varied from $0.05 \mathrm{~mm}$ to $0.15 \mathrm{~mm}$ following the pattern shown in Fig. 5.

\section{$\underline{\text { Parametric study }}$}

Apparently, the tangential interfacial stiffness depends significantly on the shear modulus 
$211 G_{a}$ of the adhesive which is under pure shear. It is therefore reasonable to propose the

212 following equation for the tangential stiffness $k_{t}$ :

213

$$
k_{t}=A G_{a}
$$

214 where $A$ is used to account for the effect of other parameters in the system. With Eq. 14, a

215 single value of $G_{a}$ was used in the parametric study, which was equal to $1111 \mathrm{MPa}$,

216 representing a typical adhesive with an elastic modulus $E_{a}$ of $3000 \mathrm{MPa}$ and a Poisson's

217 ratio of 0.35 . The parametric study was focused on finding an appropriate expression for $A$.

218

219 The shape and thickness of the adhesive layer, as well as the area of interface between 220 concrete and adhesive are also important parameters affecting the tangential stiffness in this

221 system. For a round bar centrically placed in a square groove, the geometrical parameters are 222 uniquely defined when the diameter of the NSM bar and the side length of the groove are 223 given. Therefore, in the parametric study, the bar diameter and the ratio between the side length of groove and the bar diameter (referred to as length-to-diameter ratio hereafter) were taken as the variables. Five values of bar diameter (i.e. $6 \mathrm{~mm}, 12 \mathrm{~mm}, 18 \mathrm{~mm}, 30 \mathrm{~mm}$ and 42 $\mathrm{mm}$ ), as well as four values of length-to-diameter ratio (i.e. 1.25, 1.5, 2 and 3) were used in the parametric study. The range covered by these values is deemed to be large enough for the practical application of NSM FRP bars [1]. Details of the numerical cases examined in the FE parametric study are summarized in Table 1 . For ease of reference, each numerical specimen is given a name, which starts with a letter "T" to indicate that it is a specimen for the study of tangential interfacial stiffness, followed by a letter " $\mathrm{D}$ " and a number to represent the diameter of the FRP bar, and then a letter "W" and a number to represent the side length of the square groove. 
237 By definition, it is easy to derive that the tangential interfacial stiffness is relevant to (1) the thickness of the adhesive layer; and (2) the length of the bonding line of the cross-section. The former has a minimum value of $W-D$, while the latter is related to the perimeter and thus the diameter of the FRP bar $D$. Therefore, the following equation is proposed for $A$ :

$$
A=k\left(\frac{W-D}{D}\right)^{\alpha}=k\left(\frac{W}{D}-1\right)^{\alpha}=k(R-1)^{\alpha}
$$

where $k$ and $\alpha$ are constants to be determined; $R$ (i.e. W/D) is ratio between the side length of the square groove and the diameter of the FRP bar (referred to as length-to-diameter ratio hereafter for brevity).

The results from the parametric study are summarized in Table 1. It is evident from Table 1 that the tangential interfacial stiffness $\left(k_{t}\right)$ predicted by the FE models depends almost solely on the length-to-diameter ratio $R$ (i.e. $W / D$ ), which demonstrated the validity of Eq. 15 with $R$ as the only variable. A regression analysis was conducted based on the results summarized in Table 1, leading to the following best-fit equation for the tangential interfacial stiffness:

$$
k_{t}=A G_{a}=7.1 G_{a}(R-1)^{-0.61}=7.1 G_{a}\left(\frac{1}{R-1}\right)^{0.61}
$$

A comparison between the predictions of Eq. 16 and the FE results is also provided in Table 1, which shows a very good agreement between the two: the ratios between these two sets of predictions have an average value of 0.999, a standard deviation (STD) of 0.019, and a coefficient of variation (CoV) of 0.019 . 
260 Making use of the results from the FE parametric study, the eccentricity of the tangential 261 interaction force to the centroid of the NSM bar (i.e. $y_{f}$ ) can be found in the following way:

262 (1) extract the shear stresses along a circular path which is concentric with the FRP bar, but 263 has a slightly larger diameter; (2) calculate the resultant moment induced by the shear stresses with respect to the neutral axis of the NSM bar; (3) finding the eccentricity $y_{f}$ by dividing the resultant moment by the resultant shear force which is equal to the total reaction force from the boundary. The eccentricities obtained using the above method are listed in Table 1 for all the numerical specimens. Apparently, the eccentricity $y_{f}$ is related to the width of the groove and the diameter of the FRP bar, so the following formula was proposed based on a regression analysis of the results in Table 1:

$$
y_{f}=\frac{0.165}{W^{1.12} D^{0.12}}
$$

271 A comparison between the predictions of Eq. 17 and the FE results is also provided in Table 1. A very good agreement was found between the two: the ratios between the two sets of predictions have an average value of 1.009, an STD of 0.012, and a CoV of 0.012. After $y_{f}$ is obtained, $y_{b}$ can be found by $y_{b}=d_{o}-y_{f}$.

It should be noted that the accuracy of eccentricity predicted by Eq. 17 depends on the beam height-to-groove height ratio: a larger beam height-to-groove height ratio leads to a higher accuracy. In real applications, the groove to accommodate the NSM bar is in the concrete cover and for most cases the concrete cover is usually less than nine-tenth of the beam height, which implies that the above ratio will be usually larger than ten. Therefore, Eq. 17 is applicable to most cases in real applications with good accuracy. 


\section{Normal Interfacial Stiffness}

As the length of the FRP bar is typically much larger than the width of the groove, the problem was simplified as a plain strain problem in the transverse direction when evaluating the normal interfacial stiffness $k_{n}$. Such treatment is believed to be sufficiently accurate.

Fig. 4c shows a schematic of the FE models used to obtain the normal interfacial stiffness, while Fig. 6 shows the mesh of a typical FE model (i.e. specimen N-D6-W9). Both the adhesive layer and the FRP bar were modelled using 4-node quadrangle plane strain elements with a full Gauss integration. The thickness of the plane strain elements was set to be the unit length $1 \mathrm{~mm}$, so that the normal interfacial stiffness is equal to the normal reaction force from the boundary. The mesh was obtained in a way similar to that discussed above for "T" series specimens. Similarly, a mesh convergence study was first conducted to decide on the suitable meshes for the FE models used in the present study. The resulting mesh from the convergence study had an approximate global mesh size of $0.1 \mathrm{~mm}$ and was used for all the specimens in the parametric study.

\section{$\underline{\text { Parametric study }}$}

303 Compared with the numerical specimens for tangential interfacial stiffness where the

304 adhesive layer is under pure shear, the stress state in the adhesive layer is more complex in 305 the FE models for evaluating normal interfacial stiffness. Eq. 14 is therefore not applicable 306 here. Considering that it is still a linear elastic problem, the following expression is proposed 307 for the expression of the normal interfacial stiffness: 
309 where $f\left(v_{a}\right)$ is the function used to account for the effect of the Passion's ratio of adhesive $310 v_{a}$ on the normal interfacial stiffness, and $B$ is used to account for the effect of other

311 parameters in the system.

312

313 FE analysis was first conducted to clarify the effect of Passion's ratio of adhesive on the

314 normal interfacial stiffness. A total of 20 numerical specimens were examined, which all had

315 the same elastic modulus of adhesive (i.e. $3000 \mathrm{MPa}$ ) and the same FRP bar with a diameter

316 of $12 \mathrm{~mm}$. The 20 specimens covered four groove side lengths (i.e. $15 \mathrm{~mm}, 18 \mathrm{~mm}, 24 \mathrm{~mm}$

317 and $36 \mathrm{~mm}$ ), and five values of Poisson's ratio of adhesive (i.e. 0.25, 0.3, 0.35, 0.4, 0.45)

318 (Table 2). The selected range of the Poisson's ratio is sufficiently large for commonly used epoxy-based adhesives for NSM strengthening. The results of the 20 numerical specimens showed that the Poisson's ratio only had a minor effect on the normal interfacial stiffness, affecting the normal interfacial stiffness by less than 3\% (Table 2 and Fig. 7). Therefore, in the subsequent FE analysis, the Poisson's ratio of adhesive is not adopted as a parameter and a constant value of 0.35 was used, leading to the following simple expression of the normal interfacial stiffness:

$$
k_{n}=B E_{a}
$$

327 Sixteen additional numerical specimens were examined to clarify the effect of the bar 328 diameter and the length-to-diameter ratio. These covered four values of bar diameter (i.e. 6 mm, $18 \mathrm{~mm}, 30 \mathrm{~mm}$ and $42 \mathrm{~mm}$ ) and four values of length-to-diameter ratio (i.e. 1.25, 1.5, 2 and 3). Details of these numerical specimens are summarized in Table 3. The naming system

331 for these specimens is similar to the "T" series specimens (Table 1), except that the names of 
specimens in this series each starts with a letter " $N$ " to indicate that it is a specimen for the study of normal interfacial stiffness.

\section{Proposed equation for normal interfacial stiffness}

Similar to the tangential interfacial stiffness, the normal interfacial stiffness is also deemed to be a function of the thickness of the adhesive layer and the length of the bonding line of the cross-section. The following equation is thus proposed for $B$ in Eq. 19:

$$
B=l\left(\frac{W-D}{D}\right)^{\eta}=l(R-1)^{\eta}
$$

where $l$ and $\eta$ are constants to be determined.

The results from the parametric study are summarized in Table 3, which shows that the normal interfacial stiffness $\left(k_{n}\right)$ obtained from the FE models again depends almost solely on the length-to-diameter ratio $R$ (i.e. W/D). This observation demonstrates the validity of Eq. 20 with $R$ as the only variable. A regression analysis was conducted based on the results summarized in Table 3, leading to the following best-fit equation for the normal interfacial stiffness:

$$
k_{n}=B E_{a}=4 E_{a}(R-1)^{-0.66}=4 E_{a}\left(\frac{1}{R-1}\right)^{0.66}
$$

A comparison between the predictions of Eq. 21 and the FE results is also provided in Table 3, which shows a very good agreement between the two: the ratios between these two sets of predictions have an average value of 1.002, a standard deviation (STD) of 0.021 , and a coefficient of variation (CoV) of 0.021 . 


\section{General}

With the two interfacial stiffness parameters determined by Eqs. 16 and 21 and the eccentricity tangential interaction force determined by Eq. 17, the interaction forces between the NSM bar and concrete in RC beams strengthened with an NSM round FRP bar can be predicted using Eqs. 3 to 13. To verify the proposed equations and the analytical solution, 3D FE analysis of a RC beam strengthened with an NSM round bar under a UDL were conducted using ABAQUS [24]. The FE results are presented in this section for comparison with analytical predictions from the closed-form solution.

\section{FE Modelling of an RC Beam Strengthened with a NSM Round Bar}

The modelled RC beam had a span of $2400 \mathrm{~mm}$, a height of $300 \mathrm{~mm}$ and a width of $150 \mathrm{~mm}$.

The diameter of the NSM round bar was $8 \mathrm{~mm}$ and the groove side length was $12 \mathrm{~mm}$, leading to a length-to-diameter ratio of 1.5. The NSM round bar was symmetrically placed with respect to the mid-span of the beam, with a length of $1800 \mathrm{~mm}$; the distance from the NSM bar end to the nearest support was thus $300 \mathrm{~mm}$. A UDL of $30 \mathrm{~N} / \mathrm{mm}$ was applied on the top surface of the beam. The details of the modelled beam are summarized in Table 4.

375 The mesh of the beam is shown in Fig. 8. Taking advantage of symmetry, only a quarter of 376 the beam was modelled, with symmetric boundary conditions applied (Fig. 8). All of the 377 materials were modelled using 8-node solid elements with a full Gauss integration. A gap of 2 
$\mathrm{mm}$ was left between the concrete and the NSM bar end. Considering the existence of localized stress concentration near the end of NSM bar, a graded mesh was adopted which initiated from the NSM bar end and propagating in all the three directions (i.e. longitudinal, transverse and vertical directions). This technique led to a finer mesh close to the NSM bar end as shown in Fig. 8.

383

Different from the FE models presented earlier for the interfacial stuffiness parameters, it is inconvenient to directly extract the interaction forces from the concrete nodes adjacent to the adhesive layer in the beam FE model. Therefore, the adhesive layer was deliberately partitioned before meshing (Fig. 9) to facilitate the extraction of interaction force from the FE results. The partition of adhesive layer (Fig. 9) allows the shear and normal stresses to be obtained and integrated along a predefined path to obtain the shear interaction force and the normal interaction force.

It is well known that high interaction forces (stresses) usually exist near the NSM bar end. A mesh convergence study was thus conducted with particular attention to this localized region. Four different mesh sizes, namely $0.15 \mathrm{~mm}, 0.25 \mathrm{~mm}, 0.5 \mathrm{~mm}$ and $1 \mathrm{~mm}$, were adopted in this study. In the context of a graded mesh, the above four mesh sizes represent the size of the smallest elements which are at the initiation point of the graded mesh (i.e. the bar end in this case). The tangential and normal interaction forces obtained using the four meshes are plotted in Figs. 10a and 10b respectively. Fig. 10a shows that the FE models with all the four meshes predict a tangential interaction force which first increases with the distance from the bar end until a peak value at a distance of around $1.5 \mathrm{~mm}$, and then decreases gradually with the distance. A larger mesh size generally led to a larger tangential interaction force close to the 402 bar end, but this difference caused by the mesh size was only localized within a very small 
region and vanished rapidly with the increase of the distance to the bar end. The difference

404 with the scale shown in Fig. 10a, due mainly to the free surface boundary condition at the bar end, was also noted in other similar problems [e.g. 7, 25] and is deemed to be insignificant.

Fig. 10b shows that all the meshes led to the same trend of the normal interaction force

407 except for the one with a mesh size of $1 \mathrm{~mm}$ at the initiation point of the graded mesh. The

408 difference between the results from the other three meshes was found to be very small. Based on the above discussions, it is clear that a mesh size of smaller than $0.5 \mathrm{~mm}$ at the initiation point of the graded mesh is sufficient for reasonably accurate results. In the subsequent section, results from the finest mesh examined (i.e. mesh size being $0.15 \mathrm{~mm}$ at the initiation point of the graded mesh) are used for comparison with the analytical solutions.

\section{Comparison with Analytical Solution}

414 Fig. 11 shows a comparison between the predictions of the 3D FE model and the proposed analytical solution. Fig. 11a shows that the analytical solution generally predicts tangential interaction forces which are very close to that predicted by the FE model, except for a very small region close to the NSM bar end. The error of the analytical solution in that small region is due to the fact that the analytical solution does not take into account the boundary

419 condition of zero shear stress at the bar end. The same observation was also made and discussed by existing studies for externally bonded FRP-strengthened RC beams [25]. predictions for the normal interaction force except for a small region close to the bar end.

\section{CONCLUSIONS}

425 This paper has presented an analytical solution for the interaction forces between the NSM 
426 bar and concrete in RC beams strengthened with NSM round bars. The analysis approach 427 adopted in the present study was an extension of that adopted by Zhang and Teng [7] for

428 NSM rectangular bars, which involves the use of Smith and Teng's solution [10] for plated 429 RC beams as an important basis. The key element of the proposed analytical solution is the 430 two interfacial stiffness parameters (i.e. tangential interfacial stiffness and normal interfacial 431 stiffness), which has been determined from a parametric study using simplified FE models for 432 round FRP bars embedded in a square groove. The proposed interfacial equations for the two stiffness parameters take into account of the material properties of adhesive as well as the unique geometric properties of this problem.

The validity of the proposed analytical solution has been verified using results from a sophisticated 3D FE model of a RC beam strengthened with a NSM round bar. The high interaction forces identified using the FE analysis as well as the analytical solution explain to some extent why end debonding failures commonly happen in RC beams strengthened with

440 NSM round bars. The proposed analytical solution can also be directly used to predict the 441 strength of end debonding failures in various other problems (e.g. NSM bar-strengthened timber beams) where end debonding is likely to happen when the beam is still linear elastic near the NSM bar ends.

\section{ACKNOWLEDGEMENT}

446 The authors are grateful for the financial support received from the National Natural Science

447 Foundation of China (Project No. 51308483), and the Australian Research Council through a

448 Discovery Early Career Researcher Award (Project ID: DE140101349) for the second author. 


\section{REFERENCES}

451 [1] De Lorenzis, L., and Teng, J. G. (2007). "Near-surface mounted FRP reinforcement: an emerging technique for strengthening structures.” Composites: Part B, 38(2), 119-143.

[2] Teng, J. G., Chen, J. F., Smith, S. T., and Lam, L. (2002). FRP-strengthened RC Structures, West Sussex: Wiley.

[3] Teng, J. G., De Lorenzis, L., Wang, B., Rong, L., Wong, T. N., and Lam, L. (2006). "Debonding failures of RC beams strengthened with near-surface mounted CFRP strips.” Journal of Composites for Construction, ASCE, 10(2), 92-105.

458

[4] Zhang, S.S. and Teng, J.G. (2014). "Finite element analysis of end cover separation in RC beams strengthened in flexure with FRP”, Engineering Structures, 75, 550-560.

[5] Zhang, S. S., Teng, J. G. and Yu, T. (2014). "Bond strength model for CFRP strips near-surface mounted to concrete.” Journal of Composites for Construction, ASCE, 18, SPECIAL ISSUE: 10th Anniversary of IIFC, A4014003.

[6] Zhang, S. S. Teng, J. G. and Yu, T. (2013). "Bond-slip model for CFRP strips near-surface mounted to concrete.” Engineering Structures, 56, 945-953.

[7] Zhang, S. S. and Teng, J. G. (2013) “Interaction forces in RC beams strengthened with near-surface mounted rectangular bars and strips.” Composites Part B: Engineering, 45(1), 697-709.

[8] Taljsten, B. (1997). "Strengthening of beams by plate bonding." Journal of Materials in Civil Engineering, ASCE, 9(4), 206-212.

[9] Malek, A. M., Saadatmanesh, H. and Ehsani, M. R. (1998). "Prediction of failure load of R/C beams strengthened with FRP plate due to stress concentration at the plate end." ACI Structural Journal, 95(1), 142-152. 
473 [10] Smith, S. T. and Teng, J. G. (2001). "Interfacial stresses in plated beams." Engineering $474 \quad$ Structures, 23(7), 857-871.

475 [11] Deng, J., Lee, M. M. K. and Moy, S. S. J. (2004). "Stress analysis of steel beams reinforced with a bonded CFRP plate." Composite Structures, 65(2), 205-215.

[12] Tounsi A., (2006). "Improved theoretical solution for interfacial stresses in concrete beams strengthened with FRP plate.” International Journal of Solids and Structures, 43 (14-15), 4154-4174.

[13] Tounsi A., Hassaine daouadji, T., Benyoucef, S. and Bedia, E.A.A. (2009). "Interfacial stresses in FRP-plated RC beams: Effect of adherend shear deformations." International Journal of Adhesion \& Adhesives, 29(4), 343-351.

[14] Yang, J., and Wu, Y. F. (2007). "Interfacial stresses of FRP strengthened concrete 484 beams: Effect of shear deformation." Composite Structures, 80(3), 343-351.

[15] Guenaneche, B., Tounsi, A. and Bedia, E.A. (2014). "Effect of shear deformation on interfacial stress analysis in plated beams under arbitrary loading.” International Journal of Adhesion \& Adhesives, 48, 1-13.

[16] Edalati, M. and Irani, F. (2012). “Interfacial Stresses in RC Beams Strengthened by Externally Bonded FRP/Steel Plates with Effects of Shear Deformations.” Journal of Composites for Construction, ASCE, 16(1): 60-73.

[17] Roberts, T. M. (1989). "Approximate analysis of shear and normal stress concentrations in the adhesive layer of plated RC beams." The Structural Engineer, 67(12), 229-233.

[18] Zhang, L. and Teng, J. G. (2010). "Simple General Solution for Interfacial Stresses in Plated Beams." Journal of Composites for Construction, 14(4), 434-442.

[19] Narayanamurthy, V., Chen, J.F. and Cairns, J. (2010). "A general analytical method for the analysis of interfacial stresses in plated beams under arbitrary loading." Advances in Structural Engineering, 13 (5), 975-988. 
498 [20] Narayanamurthy, V., Chen, J.F., Cairns, J. and Ramaswamy, A. (2011). "Effect of 499 shear deformation on interfacial stresses in plated beams subjected to arbitrary $500 \quad$ loading." International Journal of Adhesion \& Adhesives, 31, 862-874.

501 [21] Shen, H. S., Teng, J. G. and Yang, J. (2001). "Interfacial stresses in beams and slabs 502 bonded with thin plate.” Journal of Engineering Mechanics, ASCE, 127, 399-406.

503 [22] Yang J., Teng, J.G. and Chen, J.F. (2004). "Interfacial stresses in soffit-plated 504 reinforced concrete beams.” Proceedings of the Institution of Civil Engineers $505 \quad$ Structures and Buildings, 157(SB1), 77-89.

506 [23] Yang, J., Chen, J.F. and Teng, J.G. (2009). “Interfacial stress analysis of plated beams under symmetric mechanical and thermal loading." Construction and Building Materials, 23(9), 2973-2987.

509 [24] ABAQUS. (2012). ABAQUS 6.12 User's Manual, ABAQUS, Inc., Providence, RI.

510 [25] Teng, J. G., Zhang, J. W. and Smith, S. T. (2002). "Interfacial stresses in reinforced 511 concrete beams bonded with a soffit plate: A finite element study.” Construction and Building Materials, 16(1), 1-14. 


\section{TABLES}

Table 1. Verification of equations for the tangential interfacial stiffness and eccentricity $y_{f}$

\begin{tabular}{|c|c|c|c|c|c|c|c|c|c|c|c|}
\hline \multirow[b]{2}{*}{ Specimen } & \multirow[b]{2}{*}{$\underset{(\mathrm{mm})}{D}$} & \multirow[b]{2}{*}{$\begin{array}{c}W \\
(\mathrm{~mm})\end{array}$} & \multirow[b]{2}{*}{$\begin{array}{c}R \\
\text { (i.e. } W / D \text { ) }\end{array}$} & \multirow[b]{2}{*}{$\begin{array}{c}G_{a} \\
(\mathrm{MPa})\end{array}$} & \multicolumn{3}{|c|}{$k_{t}$} & \multicolumn{4}{|c|}{$y_{f}$} \\
\hline & & & & & $\begin{array}{c}\mathrm{FE} \\
\text { result } \\
\left(\mathrm{N} / \mathrm{mm}^{2}\right)\end{array}$ & $\begin{array}{l}\text { Prediction } \\
\text { of Eq. } 16 \\
\left(\mathrm{~N} / \mathrm{mm}^{2}\right)\end{array}$ & $\begin{array}{c}\text { Prediction } \\
/ \\
\text { FE }\end{array}$ & $\begin{array}{c}y_{f} \\
\text { From FE analysis } \\
(\mathrm{mm})\end{array}$ & $\begin{array}{c}y_{f} / D \\
\text { From FE analysis }\end{array}$ & $\begin{array}{l}\text { Prediction } \\
\text { of Eq. } 17\end{array}$ & $\begin{array}{c}\text { Prediction } \\
/ \\
\text { FE }\end{array}$ \\
\hline T-D6-W7.5 & 6 & 7.5 & 1.25 & 1111 & 18732.2 & 18402.8 & 0.982 & 0.770 & 0.128 & 0.129 & 1.004 \\
\hline T-D6-W9 & 6 & 9 & 1.5 & 1111 & 11869.9 & 12057.4 & 1.016 & 0.634 & 0.106 & 0.105 & 0.988 \\
\hline T-D6-W12 & 6 & 12 & 2 & 1111 & 7734.7 & 7900.0 & 1.021 & 0.456 & 0.076 & 0.076 & 0.999 \\
\hline T-D6-W18 & 6 & 18 & 3 & 1111 & 5275.8 & 5176.1 & 0.981 & 0.292 & 0.049 & 0.048 & 0.984 \\
\hline T-D12-W15 & 12 & 15 & 1.25 & 1111 & 18734.7 & 18402.8 & 0.982 & 1.514 & 0.126 & 0.129 & 1.020 \\
\hline T-D12-W18 & 12 & 18 & 1.5 & 1111 & 11872.2 & 12057.4 & 1.016 & 1.257 & 0.105 & 0.105 & 0.998 \\
\hline T-D12-W24 & 12 & 24 & 2 & 1111 & 7734.9 & 7900.0 & 1.021 & 0.907 & 0.076 & 0.076 & 0.999 \\
\hline T-D12-W36 & 12 & 36 & 3 & 1111 & 5275.9 & 5176.1 & 0.981 & 0.582 & 0.048 & 0.048 & 1.004 \\
\hline T-D18-W22.5 & 18 & 22.5 & 1.25 & 1111 & 18735.1 & 18402.8 & 0.982 & 2.258 & 0.125 & 0.129 & 1.028 \\
\hline T-D18-W27 & 18 & 27 & 1.5 & 1111 & 11872.4 & 12057.4 & 1.016 & 1.862 & 0.103 & 0.105 & 1.017 \\
\hline T-D18-W36 & 18 & 36 & 2 & 1111 & 7734.9 & 7900.0 & 1.021 & 1.353 & 0.075 & 0.076 & 1.012 \\
\hline T-D18-W24 & 18 & 54 & 3 & 1111 & 5275.8 & 5176.1 & 0.981 & 0.868 & 0.048 & 0.048 & 1.004 \\
\hline T-D30-W37.5 & 30 & 37.5 & 1.25 & 1111 & 18720.3 & 18402.8 & 0.983 & 3.752 & 0.125 & 0.129 & 1.028 \\
\hline T-D30-W45 & 30 & 45 & 1.5 & 1111 & 11870.9 & 12057.4 & 1.016 & 3.094 & 0.103 & 0.105 & 1.017 \\
\hline T-D30-W60 & 30 & 60 & 2 & 1111 & 7735.1 & 7900.0 & 1.021 & 2.251 & 0.075 & 0.076 & 1.012 \\
\hline T-D30-W90 & 30 & 90 & 3 & 1111 & 5275.5 & 5176.1 & 0.981 & 1.441 & 0.048 & 0.048 & 1.004 \\
\hline T-D42-W52.5 & 42 & 52.5 & 1.25 & 1111 & 18735.2 & 18402.8 & 0.982 & 5.237 & 0.125 & 0.129 & 1.028 \\
\hline T-D42-W63 & 42 & 63 & 1.5 & 1111 & 11878.3 & 12057.4 & 1.015 & 4.326 & 0.103 & 0.105 & 1.017 \\
\hline T-D42-W84 & 42 & 84 & 2 & 1111 & 7736.5 & 7900.0 & 1.021 & 3.145 & 0.075 & 0.076 & 1.012 \\
\hline T-D42-W126 & 42 & 126 & 3 & 1111 & 5279.2 & 5176.1 & 0.980 & 2.012 & 0.048 & 0.048 & 1.004 \\
\hline Average $=$ & & & & & & & 0.999 & & & & 1.009 \\
\hline STD = & & & & & & & 0.019 & & & & 0.012 \\
\hline $\mathrm{CoV}=$ & & & & & & & 0.019 & & & & 0.012 \\
\hline
\end{tabular}


Table 2. Influence of Poisson's ratio on the normal interfacial stiffness

\begin{tabular}{|c|c|c|c|c|c|c|c|c|c|c|c|c|c|}
\hline \multirow[t]{2}{*}{ Specimen } & \multirow{2}{*}{$\underset{(\mathrm{mm})}{D}$} & \multirow{2}{*}{$\begin{array}{c}W \\
(\mathrm{~mm})\end{array}$} & \multirow{2}{*}{$\begin{array}{c}R \\
\text { (i.e. } W / D \text { ) }\end{array}$} & \multicolumn{5}{|c|}{$\begin{array}{l}\text { FE result } \\
\left(\mathrm{N} / \mathrm{mm}^{2}\right)\end{array}$} & \multicolumn{5}{|c|}{$\begin{array}{l}\text { Error of the FE results } \\
\text { with respect to the FE prediction with } \\
\qquad v_{a}=0.35\end{array}$} \\
\hline & & & & $v_{a}=0.25$ & $v_{a}=0.3$ & $v_{a}=0.35$ & $v_{a}=0.4$ & $v_{a}=0.45$ & $v_{a}=0.25$ & $v_{a}=0.3$ & $v_{a}=0.35$ & $v_{a}=0.4$ & $v_{a}=0.45$ \\
\hline N-D12-W15 & 12 & 15 & 1.25 & 30248.8 & 30188.2 & 30282.0 & 30548.0 & 31012.7 & $-0.11 \%$ & $-0.31 \%$ & 0 & $0.88 \%$ & $2.41 \%$ \\
\hline N-D12-W18 & 12 & 18 & 1.5 & 18664.5 & 18596.5 & 18618.5 & 18739.6 & 18974.2 & $0.25 \%$ & $-0.12 \%$ & 0 & $0.65 \%$ & $1.91 \%$ \\
\hline N-D12-W24 & 12 & 24 & 2 & 11783.9 & 11708.9 & 11685.8 & 11719.2 & 11816.1 & $0.84 \%$ & $0.20 \%$ & 0 & $0.29 \%$ & $1.12 \%$ \\
\hline N-D12-W36 & 12 & 36 & 3 & 7888.1 & 7812.4 & 7768.0 & 7756.8 & 7782.3 & $1.55 \%$ & $0.57 \%$ & 0 & $-0.14 \%$ & $0.18 \%$ \\
\hline
\end{tabular}


Table 3. Verification of the normal interfacial stiffness equation

\begin{tabular}{|c|c|c|c|c|c|c|c|c|}
\hline Specimen & $\underset{(\mathrm{mm})}{D}$ & $\begin{array}{c}W \\
(\mathrm{~mm})\end{array}$ & $\begin{array}{c}R \\
\text { (i.e. } W / D)\end{array}$ & $\begin{array}{c}E_{a} \\
(\mathrm{MPa})\end{array}$ & $v_{a}$ & $\begin{array}{c}\text { FE } \\
\text { result } \\
\left(\mathrm{N} / \mathrm{mm}^{2}\right)\end{array}$ & $\begin{array}{l}\text { Prediction } \\
\text { of Eq. } 21 \\
\left(\mathrm{~N} / \mathrm{mm}^{2}\right)\end{array}$ & $\begin{array}{c}\text { Prediction } \\
/ \\
\text { FE }\end{array}$ \\
\hline N-D6-W7.5 & 6 & 7.5 & 1.25 & 3000 & 0.35 & 30282.0 & 29959.9 & 0.989 \\
\hline N-D6-W9 & 6 & 9 & 1.5 & 3000 & 0.35 & 18618.4 & 18961.0 & 1.018 \\
\hline N-D6-W12 & 6 & 12 & 2 & 3000 & 0.35 & 11685.8 & 12000.0 & 1.027 \\
\hline N-D6-W18 & 6 & 18 & 3 & 3000 & 0.35 & 7768.0 & 7594.5 & 0.978 \\
\hline N-D12-W15 & 12 & 15 & 1.25 & 3000 & 0.35 & 30282.0 & 29959.9 & 0.989 \\
\hline N-D12-W18 & 12 & 18 & 1.5 & 3000 & 0.35 & 18618.5 & 18961.0 & 1.018 \\
\hline N-D12-W24 & 12 & 24 & 2 & 3000 & 0.35 & 11685.8 & 12000.0 & 1.027 \\
\hline N-D12-W36 & 12 & 36 & 3 & 3000 & 0.35 & 7768.0 & 7594.5 & 0.978 \\
\hline N-D18-W22.5 & 18 & 22.5 & 1.25 & 3000 & 0.35 & 30281.9 & 29959.9 & 0.989 \\
\hline N-D18-W27 & 18 & 27 & 1.5 & 3000 & 0.35 & 18618.6 & 18961.0 & 1.018 \\
\hline N-D18-W36 & 18 & 36 & 2 & 3000 & 0.35 & 11685.8 & 12000.0 & 1.027 \\
\hline N-D18-W24 & 18 & 54 & 3 & 3000 & 0.35 & 7768.1 & 7594.5 & 0.978 \\
\hline N-D30-W37.5 & 30 & 37.5 & 1.25 & 3000 & 0.35 & 30282.0 & 29959.9 & 0.989 \\
\hline N-D30-W45 & 30 & 45 & 1.5 & 3000 & 0.35 & 18618.7 & 18961.0 & 1.018 \\
\hline N-D30-W60 & 30 & 60 & 2 & 3000 & 0.35 & 11685.8 & 12000.0 & 1.027 \\
\hline N-D30-W90 & 30 & 90 & 3 & 3000 & 0.35 & 7768.1 & 7594.5 & 0.978 \\
\hline N-D42-W52.5 & 42 & 52.5 & 1.25 & 3000 & 0.35 & 30282.1 & 29959.9 & 0.989 \\
\hline N-D42-W63 & 42 & 63 & 1.5 & 3000 & 0.35 & 18619.0 & 18961.0 & 1.018 \\
\hline N-D42-W84 & 42 & 84 & 2 & 3000 & 0.35 & 11686.0 & 12000.0 & 1.027 \\
\hline N-D42-W126 & 42 & 126 & 3 & 3000 & 0.35 & 7768.2 & 7594.5 & 0.978 \\
\hline Average $=$ & & & & & & & & $1.002 *$ \\
\hline STD = & & & & & & & & $0.021 *$ \\
\hline $\mathrm{CoV}=$ & & & & & & & & $0.021 *$ \\
\hline
\end{tabular}

Note: * the calculation of statistic values took into account the specimens listed in Table 2

with different Poisson’s ratios. 
Table 4. Geometric and material properties of the modelled beams

\begin{tabular}{c|c|c|c|c|c}
\hline Component & $\begin{array}{c}\text { Width } \\
(\mathrm{mm})\end{array}$ & Height $(\mathrm{mm})$ & $\begin{array}{c}\text { Length } \\
(\mathrm{mm})\end{array}$ & $\begin{array}{c}\text { Elastic modulus } \\
(\mathrm{MPa})\end{array}$ & $\begin{array}{c}\text { Poisson's } \\
\text { ratio }\end{array}$ \\
\hline Beam & 150 & 300 & 2400 & 20000 & 0.18 \\
\hline Groove & 12 & 12 & 1800 & NA & NA \\
\hline Adhesive & NA & $\begin{array}{c}2 \\
\text { (smallest thickness) }\end{array}$ & 1800 & 3000 & 0.35 \\
\hline NSM bar & \multicolumn{2}{|c|}{8 (diameter) } & 1800 & 200000 & 0.3 \\
\hline
\end{tabular}




\section{FIGURES}

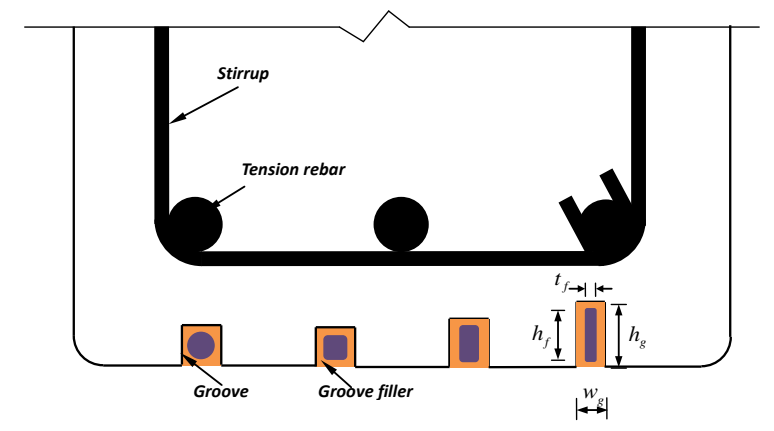

Figure 1. Schematic of NSM FRP strengthening systems

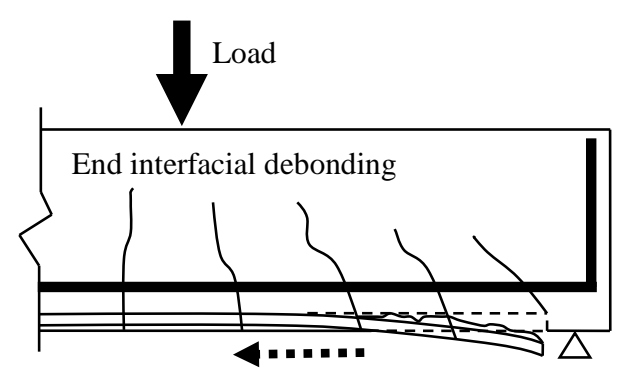

(a) End interfacial debonding

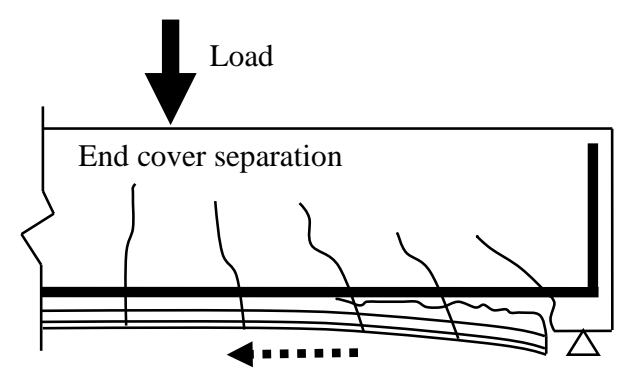

(b) End cover separation

Figure 2. Schematic of end debonding failures 


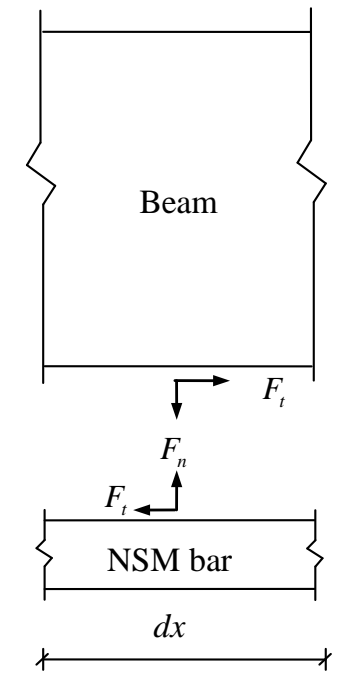

(a) Interaction forces

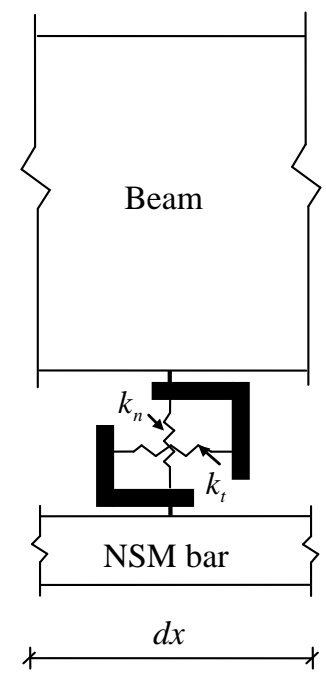

(b) Interfacial springs

Figure 3. Simplified interaction between a beam and an NSM bar: (a) Interaction forces; and (b) Interfacial springs 


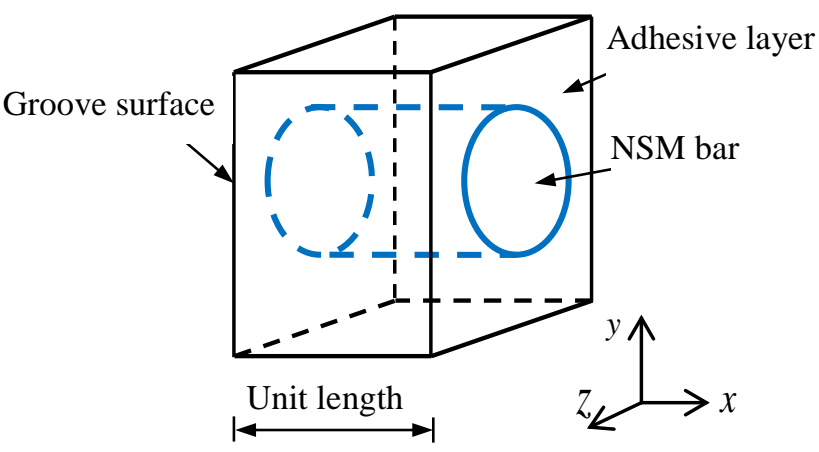

(a) Unit-length segment of NSM bar and adhesive layer
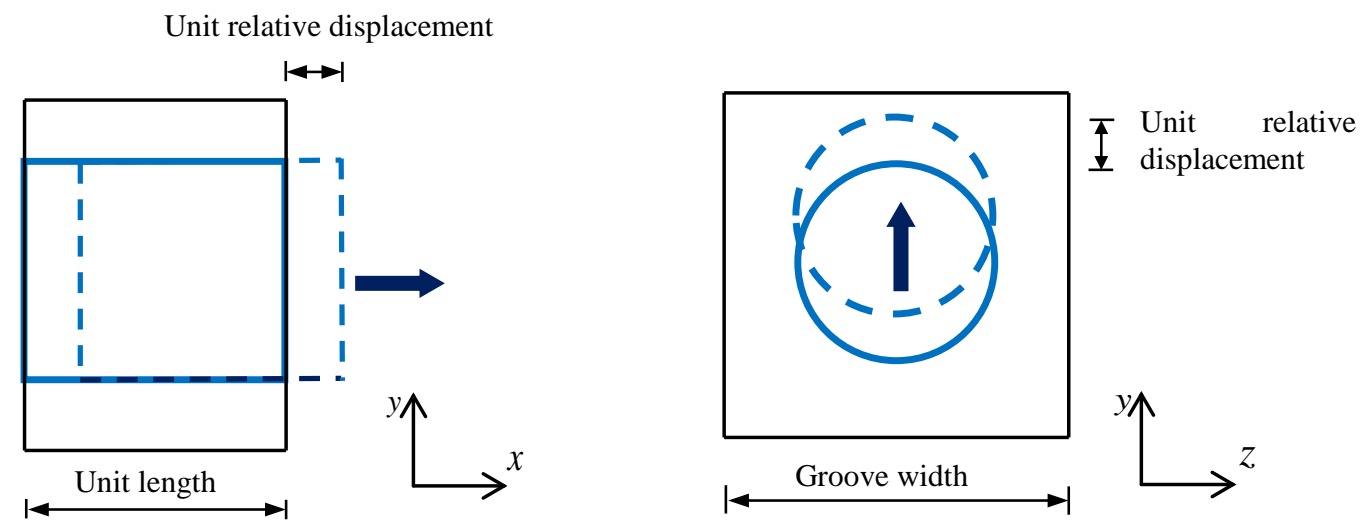

(b) Tangential interfacial stiffness $k_{t}$

(c) Normal interfacial stiffness $k_{n}$

Figure 4. Interfacial stiffness parameters as interaction forces due to a unit relative displacement: (a) Unit-length segment of NSM bar and adhesive layer; (b) Tangential interfacial stiffness $k_{t}$; and (c) Normal interfacial stiffness $k_{n}$ 


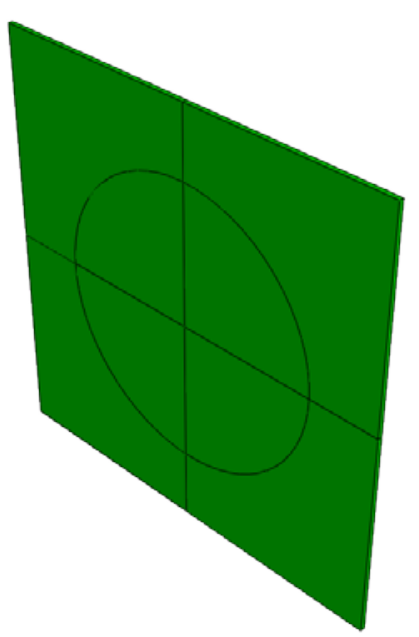

(a) partition before meshing

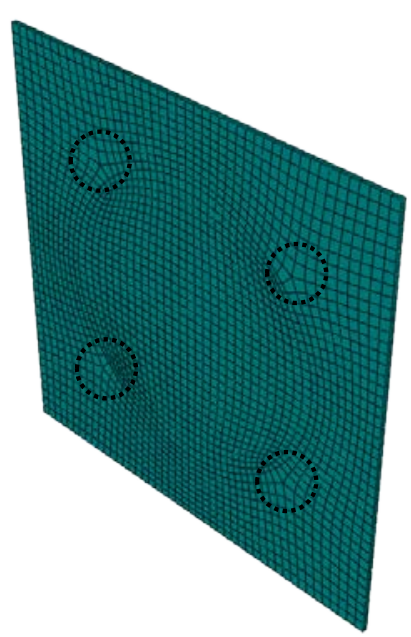

(b) mesh

Figure 5. Typical mesh of a specimen used to calculate the tangential interfacial stiffness:

(a) Partition before meshing; and (b) Mesh 


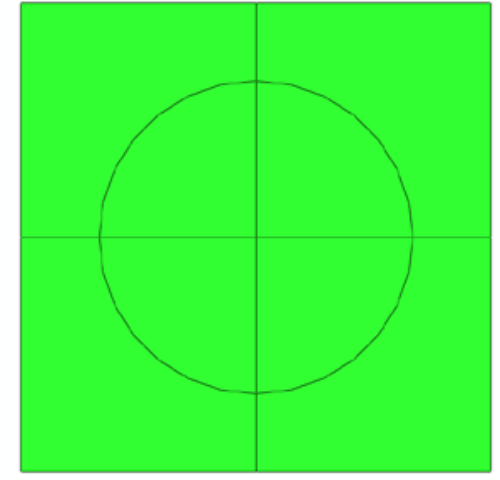

(a) partition before meshing

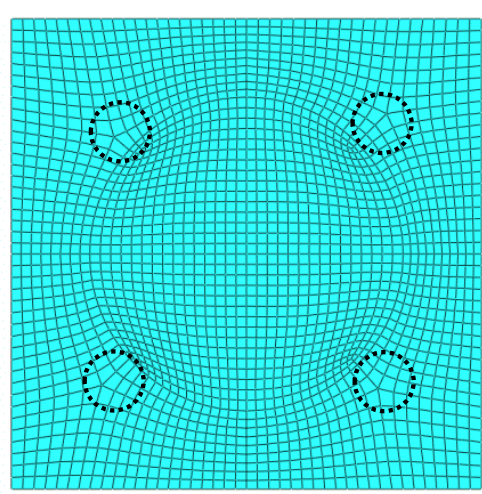

(b) mesh

Figure 6. Typical mesh of a specimen used to calculate the normal interfacial stiffness: (a) Partition before meshing; and (b) Mesh 


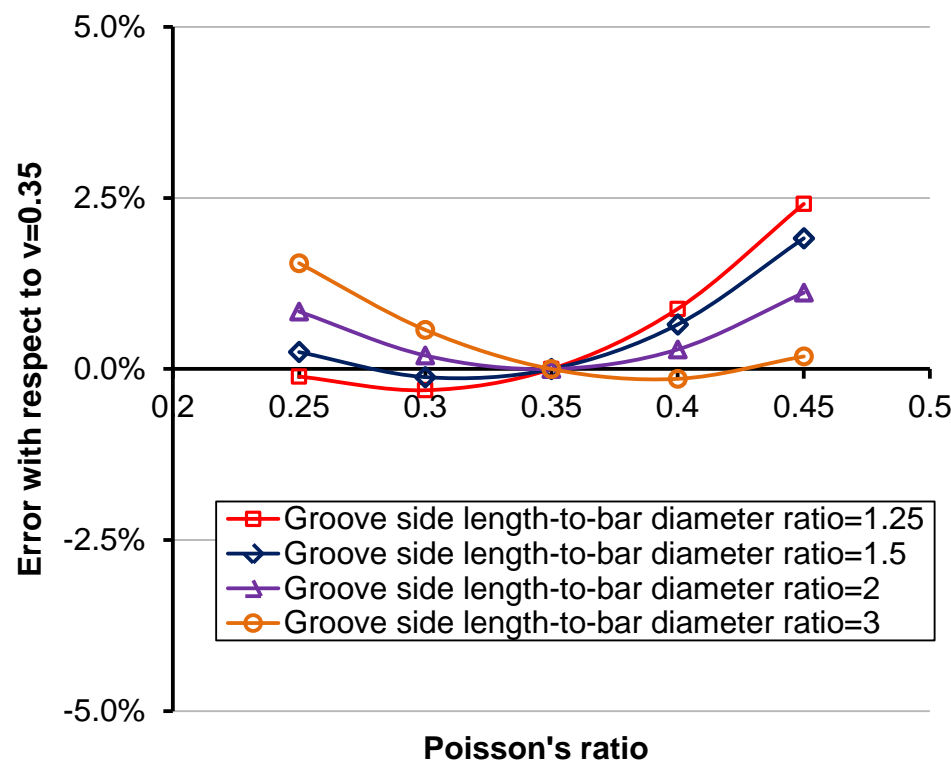

Figure 7. Effect of Poisson's ratio on the normal interfacial stiffness 


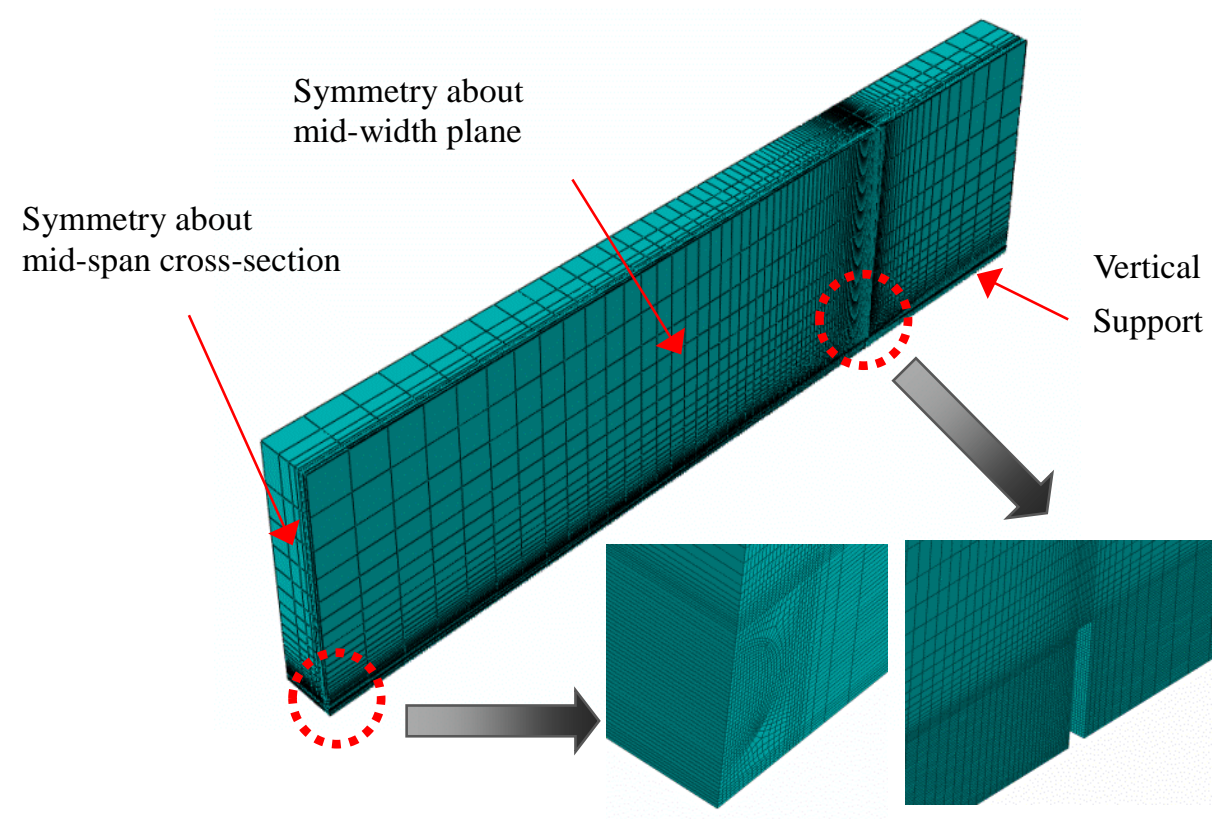

Figure 8. Mesh of RC beam strengthened with an NSM round bar 


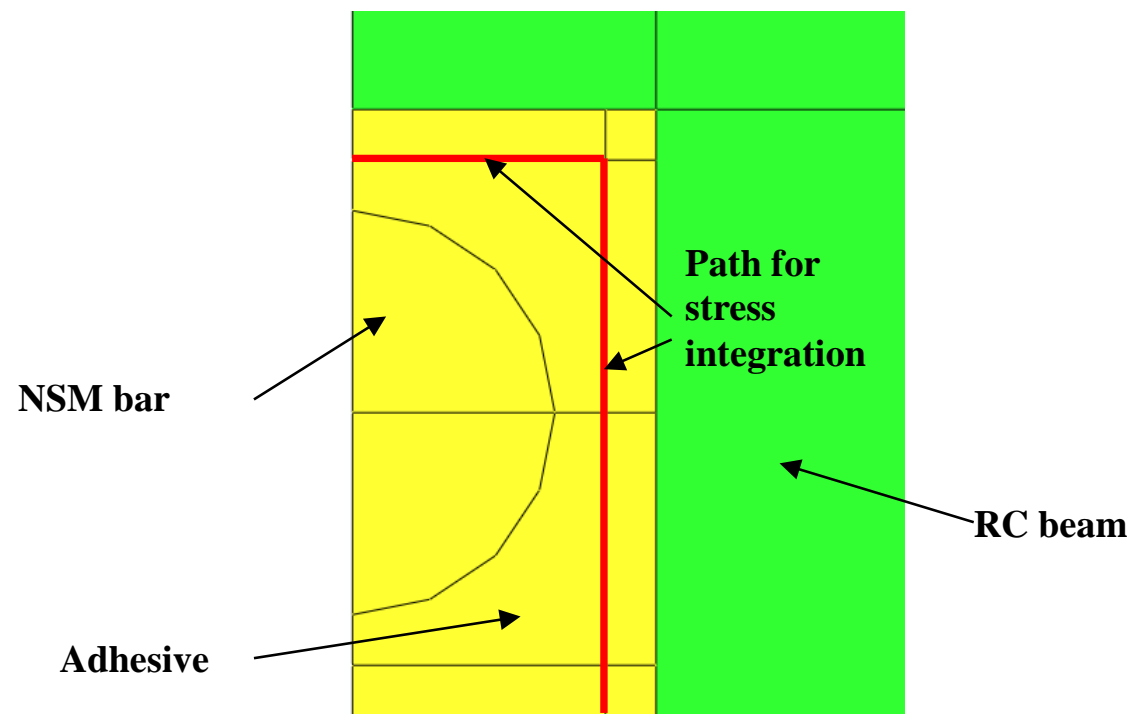

Figure 9. Partition of adhesive to form a path for stress integration 


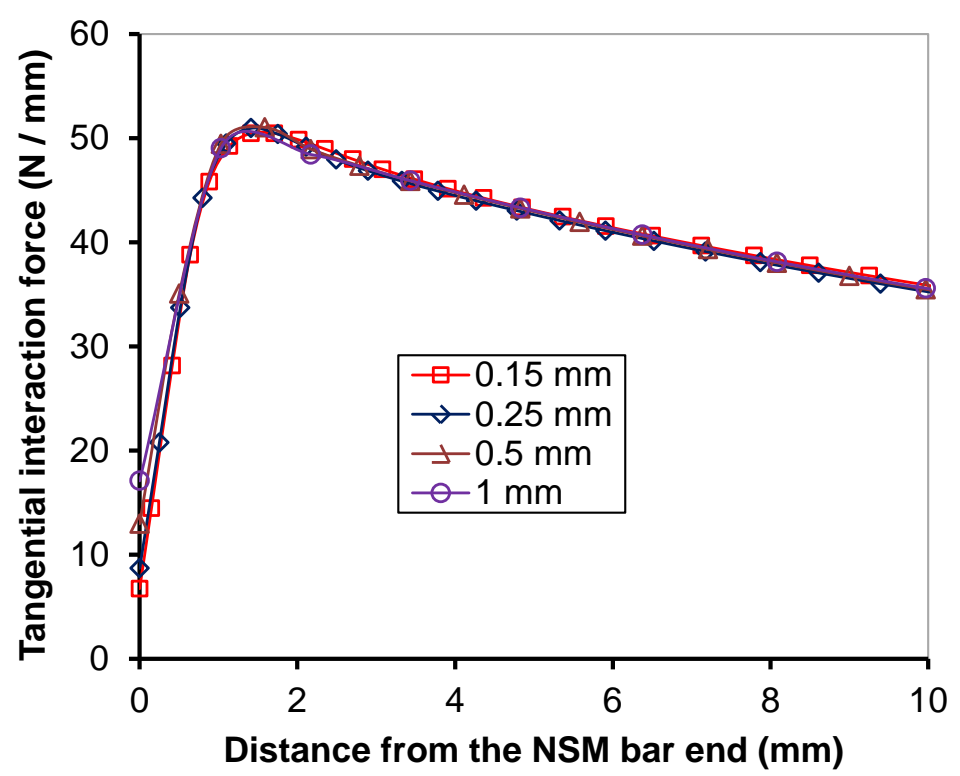

(a) Tangential interaction force

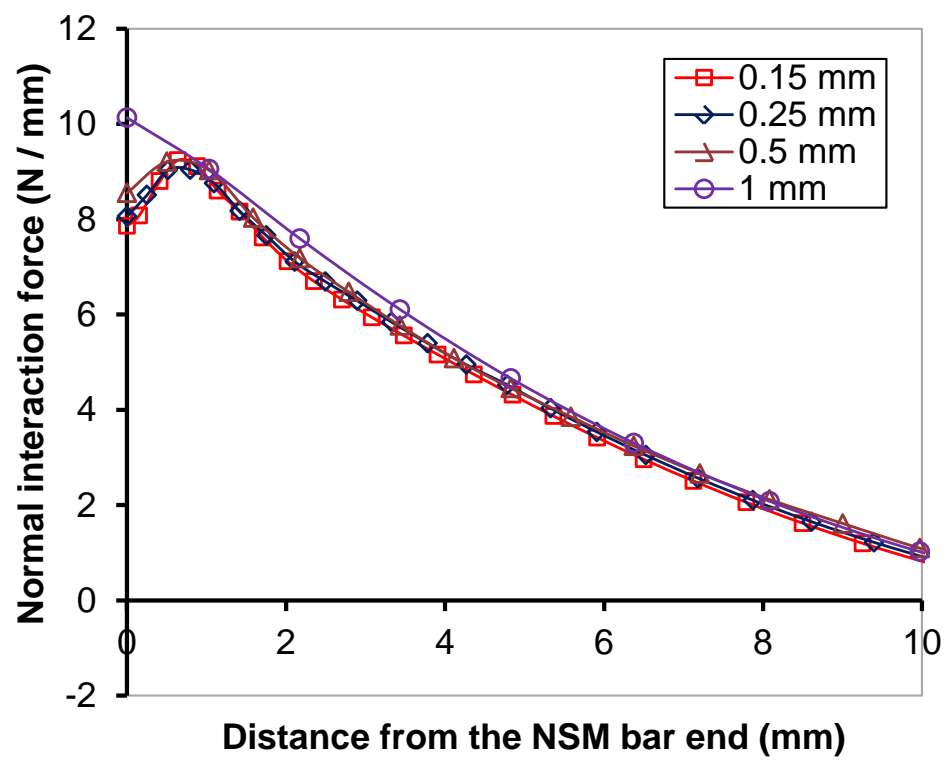

(b) Normal interaction force

Figure 10. Mesh convergence study of FE modelling: (a) Tangential interaction force; and (b) Normal interaction force 


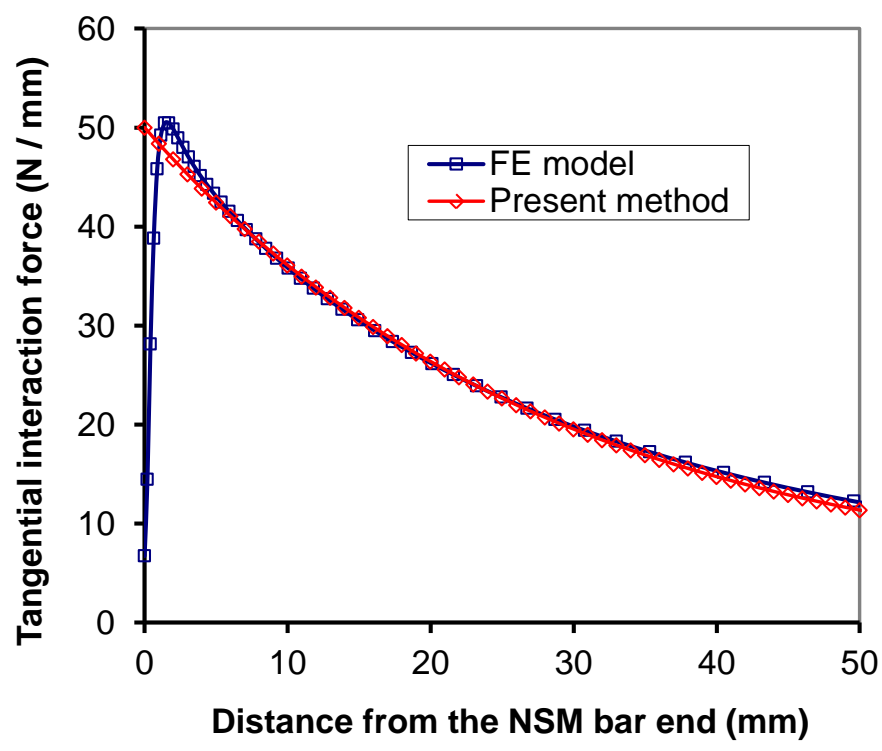

(a) Tangential interaction force

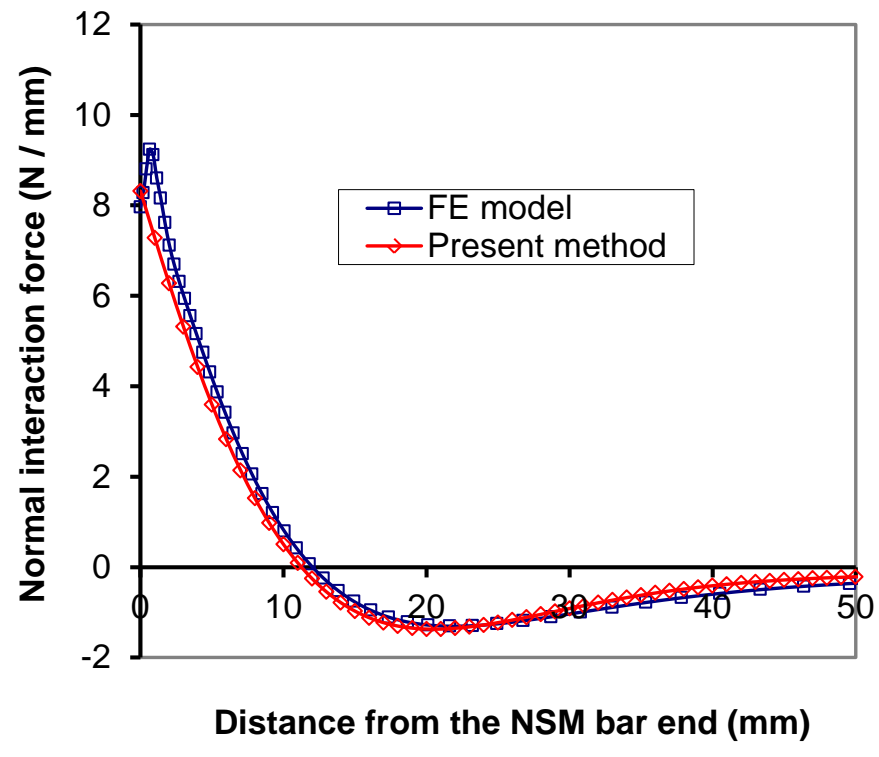

(b) Normal interaction force

Figure 11. Comparison between FE analysis and analytical solution: (a) Tangential interaction force; and (b) Normal interaction force 